\title{
Obesity and health: why slim?
}

\author{
BY MARY A. T. FLYNN AND MICHAEL J. GIBNEY \\ Department of Clinical Medicine, Trinity College Medical School, St James's Hospital, Dublin 8, \\ Republic of Ireland
}

The health risks of obesity are summarized in terms of disease in Fig. 1. Obesity is associated with a higher mortality incidence from cerebrovascular disease, coronary heart disease, diabetes mellitus and cancer of the breast, colon, endometrium and prostate (Lew \& Garfinkel, 1979). Potent cardiovascular disease risk factors such as hypertension and hypercholesterolaemia have also been associated with overweight and obesity (Van Itallie, 1985). Digestive disorders implicated include hiatus hernia and gall-bladder disease (Friedman et al. 1966). Although information on the association of osteoarthritis and obesity is contradictory, the studies that do show an increased prevalence of osteoarthritis in obese persons indicate the knee as the most frequently involved joint (Bray, 1985). That gout is commoner in obese persons is supported by information from the Framingham Study (Kannel \& Gordon, 1979).

While the strength of these obesity and disease associations is variable, the strongest evidence exists for the cardiovascular disease association. In the American Cancer Society Study of 750000 men and women coronary heart disease was the major disease responsible for the higher mortality among persons who were overweight compared with those in the average weight range. For example, mortality among men and women $30-40 \%$ heavier than average was nearly $50 \%$ higher than those of average weight; among those more than $40 \%$ heavier than average, it was nearly $90 \%$ higher than those of average weight (Lew \& Garfinkel, 1979).

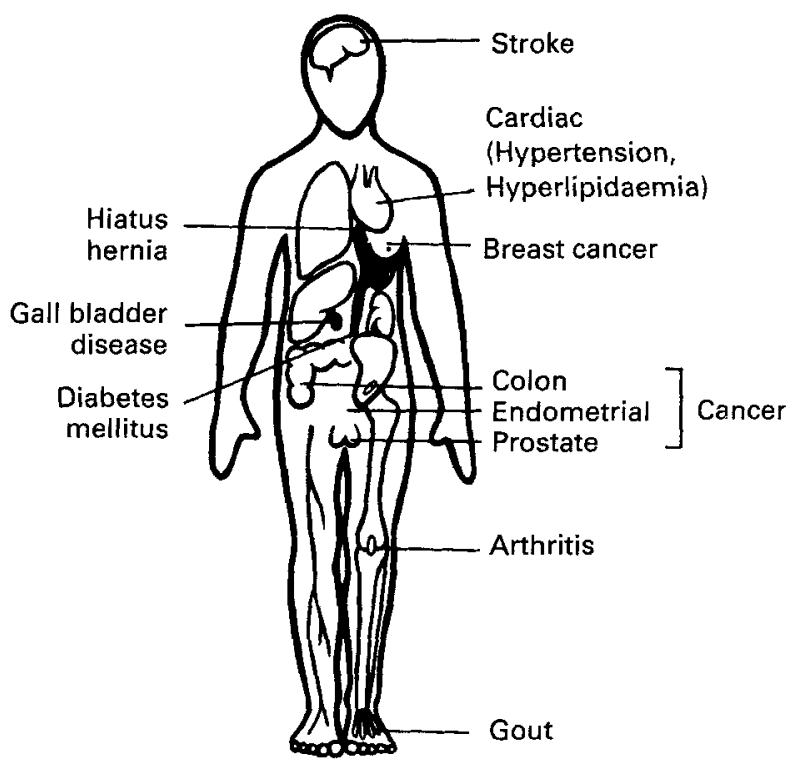

Fig. 1. Health risks associated with obesity. 
This increasing prevalence of coronary heart disease as weight increases beyond normal limits and into the area of massive obesity, is true for all disorders associated with obesity. When obesity becomes massive the term morbid is used. This describes obesity when body-weight equals or exceeds $45.4 \mathrm{~kg}$ (100 lb) above the optimal body-weight-forheight. Alternatively obesity is said to be morbid when body-weight is double the optimal body-weight.

In addition to increased morbidity and mortality from disorders described, other health problems appear at critical levels of severe obesity, thereby described as 'threshold conditions'. These include: increased incidence of sudden death (Hubert et al. 1983), congestive cardiac failure (Hubert et al. 1983), pulmonary dysfunction (Burnwell et al. 1956), sleep apnea (Victor et al. 1984), liver steatosis (Buchwald et al. 1974), renal dysfunction (Weisinger et al. 1974) and infertility (Hartz et al. 1979). It is noteworthy that several of these 'threshold conditions' regress with weight loss, e.g. pulmonary dysfunction (Victor et al. 1984), renal dysfunction (Weisinger et al. 1974) and endocrine disorders associated with infertility (Glass et al. 1978; Kopelman et al. 1981). A further limitation of massive obesity that should not be neglected in any assessment of health hazards, is functional impairment. A sickness impairment profile shows how serious this is when massively obese persons were found to be more disabled than those with severe disabling chronic conditions such as Crohn's disease and non-alcoholic liver cirrhosis (Kral, 1985).

In assessing the health risks of obesity, information about its effect on life expectancy is obviously very important. There are, however, conflicting reports on the association between body-weight and longevity with the shape of the curve relating weight to all-cause mortality being variously described as linear (Society of Actuaries, 1959), J-shaped or even U-shaped (Andres, 1980; Keys, 1980; Lew, 1985). This increased risk of death seen in lean people in the currently accepted desirable weight range associated with lowest mortality confuses the association of overweight and mortality (Andres, 1980; Keys, 1980).

There is increasing evidence, however, that the discrepancies in findings may be due to methodological biases (Manson et al. 1987). The various sources of bias include:

(1) Inadequate control for smoking. This can be a major potential source of bias as virtually every study has found cigarette smoking to be more prevalent among lean subjects (Manson et al. 1987). In the Framingham cohort, the percentage of men smoking cigarettes at entry ranged from 55 in the most overweight group to more than 80 in the lowest relative-weight category (Garrison et al. 1983). Since cigarette smoking is a strong risk factor for mortality and also has an independent inverse association with adiposity, failure to control for its effects will produce a high mortality in lean subjects. Thus, any observed crude relationship between relative weight and mortality is likely to be confounded by smoking.

Those studies where the confounding effects of cigarette smoking are controlled for suggest that, except for the very lean, relative weight has a direct relationship with mortality. When the Framingham data were analysed separately for male smokers and non-smokers a direct relationship between relative weight and mortality was apparent in non-smokers; and, among smokers, in all but the leanest group. Thus, it was demonstrated in this study that even those men who were near the average weight (about $20 \%$ above the desirable weight) showed appreciably elevated mortality, which is contrary to the view that moderate overweight carries no risk (Garrison et al. 1983). 
The results of the American Cancer Society Study (Lew, 1985) support these findings. This investigation, involving 750000 men and women, presented mortality ratios by smoking habit. Among the subgroup who never smoked, the mortality rate was clearly lower among men and women weighing less than average compared with those above average, although a modest increase was observed in the female group. Among smokers, the excess mortality among the leanest group was largely due to cancers of the lung and bladder (diseases directly attributable to cigarette smoking).

A recent report from the British Heart Study also provides strong evidence of the impact of cigarette smoking on body-weight and mortality (Wannamethee \& Shaper, 1989). Here it was found that lean men who had never smoked had the lowest mortality, thereafter mortality increased with increasing body mass index (BMI). In this, as in most other studies (Garrison et al. 1983), the number of very lean men who had never smoked was too small to draw any conclusions. It has been suggested that those workers who did find an increased mortality in lean non-smokers (Vandenbrouche et al. 1984) failed to separate never smokers from former smokers and also do not distinguish between lean $\left(B M I>20<22 \mathrm{~kg} / \mathrm{m}^{2}\right.$ ) and very lean $\left(\mathrm{BMI}<20 \mathrm{~kg} / \mathrm{m}^{2}\right.$ ) subjects (Wannamethee \& Shaper, 1989).

(2) Exclusion of pre-existing morbid conditions. A popular explanation for the increased demise of the very lean non-smokers, observed in several studies (Lew \& Garfinkel, 1979; Wannamethee \& Shaper, 1989), is that these subjects are very lean due to the pre-existence of a morbid condition. In other words they were very lean because they were very sick and not very sick because they were very lean.

Approaches that have been used to minimize the inclusion of such 'very sick lean people' in mortality studies, include: (a) the careful screening of the patient population (Society of Actuaries, 1959, 1980); (b) the exclusion of subjects experiencing substantial weight loss (i.e. $\geq 4.5 \mathrm{~kg}$ ) in the year previous to the study (Society of Actuaries, 1959, 1980; Lew \& Garfinkel, 1979). A further approach, which can be used instead of or in addition to the first two, is the separate analysis of early $v$. later mortality. Examination of life insurance data by duration of follow-up clearly demonstrates the potential impact of underlying disease on early mortality; mortality ratios in the most underweight group declined from 127 to $150 \%$ during the first 20 years of follow-up, while those in the most overweight group increased from 106 to $131 \%$ during the same period (Society of Actuaries, 1980; Lew, 1985). In the second decade of follow-up the lowest mortality rate occurred in the below-average-weight groups. Lending further support to the role of decreased body-weights as a harbinger, rather than a cause, of early death is that mortality in the early years of follow-up was commonly due to cancer, respiratory disease and other disorders likely to have caused weight loss (Society of Actuaries, 1980).

\section{NOT ALL OBESE PERSONS ARE AT THE SAME RISK OF ILL HEALTH}

\section{Factors influencing the health risks of obesity}

Age. Data from the NHANES II Study, on the prevalences of major cardiovascular disease risk factors in overweight compared with non-overweight Americans, is given in Table 1 (Van Itallie, 1985). This clearly shows how obesity (defined in this cohort as BMI $\geq 27.8$ in men and $B M I \geq 27.3$ in women) at younger ages carries greatest risk.

Hypertension is defined as systolic blood pressure (BP) $\geq 160 \mathrm{~mm} \mathrm{Hg}$ or diastolic BP $\geq 95 \mathrm{~mm} \mathrm{Hg}$, or both, and persons taking anti-hypertensive medication. For Americans 
Table 1. The effect of age on the relative risk of obesity (from Van Itallie (1985))

\begin{tabular}{lcc}
\hline \hline Age-range (years) ... & $20-45$ & $45-75$ \\
& & \\
Disorder & $5 \cdot 6$ & $2 \cdot 0$ \\
Hypertension & $2 \cdot 1$ & $1 \cdot 0$ \\
Hypercholesterolaemia & $3 \cdot 8$ & $2 \cdot 0$ \\
Diabetes mellitus & Overweight in men BMI $\geq 27 \cdot 8$ \\
NHANES II & Overweight in women BMI $\geq 27 \cdot 3$ \\
\hline
\end{tabular}

aged 20-45 years, the relative risk of hypertension was 5.6 times that of non-overweight Americans in the same age-group. In contrast, the relative risk among overweight Americans aged 45-75 years was double that of non-overweight adults in the same age-range (Van Itallie, 1985). Elevated blood cholesterol was defined as $\geq 6.5 \mathrm{mmol} / \mathrm{l}$ (2500 mg/l). Among overweight Americans aged 20-45 years, the relative risk of hypercholesterolaemia was $2 \cdot 1$ times that of non-overweight Americans in the same age-group. Surprisingly, among Americans in the 45-75 years age-range, overweight did not affect the risk of hypercholesterolaemia (Van Itallie, 1985). Diabetes mellitus was diagnosed on a patient's reporting that a physician had diagnosed diabetes mellitus on a $2 \mathrm{~h}$ oral glucose tolerance test. Among overweight Americans aged 20-45 years the relative risk was 3.8 times that for non-overweight Americans in the same age group. Among overweight Americans aged 45-75 years, the relative risk for diabetes mellitus was about twice that for non-overweight persons in the same age-group (Van Itallie, 1985).

That obesity is more harmful when it occurs in younger adults is also reflected in mortality data. The results of several large prospective studies suggest more deleterious consequences from obesity at younger ages compared with later in life (Rabkin et al. 1977; The Pooling Project Research Group, 1978; Society of Actuaries, 1980; Rhoads \& Kagan, 1983). This has led to suggestions that the weight-for-height tables should be age adjusted. Such tables have been proposed and they designate lower weight standards for younger adults but allow higher weight standards for older adults, than previously recommended (Andres et al. 1985). These tables have been criticized, however, as they are based on actuarial data that did not take smoking into account (Manson et al. 1987). Although justification for age-adjusted weight-for-height tables must await evidence from other sources, there is nonetheless, substantial evidence that obesity in younger adults has particularly harmful effects on health.

This age effect also helps to illustrate the fallacy of the belief that being slightly overweight may be advantageous (Keys, 1980). The studies on which this conclusion was based dealt with men who were in the $40+$ years age category and should not be extended to younger adults where the recommended weight range (BMI $20-25 \mathrm{~kg} / \mathrm{m}^{2}$ ) seems to apply.

Cigarette smoking. Obese people who smoke are at greatly increased risk of ill health due to an adverse interaction between cigarette smoking and obesity.

Hypertension, hyperlipidaemia and diabetes mellitus. Vulnerability to the effects of obesity may be expressed in the development of hypertension, hyperlipidaemia or non-insulin-dependent diabetes mellitus (NIDDM). The risk of obesity is at least 
partially mediated through increases in these potent cardiovascular risk factors, as described previously (p. 413). This has led to serious questioning of the practice whereby such biological effects of obesity are controlled for, when establishing the effects of obesity on health (Report on Obesity, 1983; Manson et al. 1987).

Unknown factors which affect the vulnerability of obese persons. All the previously described factors which influence the effect obesity has on health, are easily defined, e.g. age, cigarette smoking, presence of cardiovascular disease risk factors. Two factors will be introduced which are very likely to influence the relationship between obesity and life expectancy, but are less easily measured. For these reasons their effects are largely unknown. The first of these unknown entities concerns nutritional factors. The effect of high intakes of saturated fat or salt may become manifest as hypercholesterolaemia or hypertension. The effects of other nutritional factors may be unmarked, for example:

(1) some obese people may have lower intakes of vital nutrients which increase their mortality risk, e.g. lower vitamin A intakes may predispose them to increased cancer risk (Meyskens, 1990); or lower intakes of antioxidants may predispose them to increased ischaemic heart disease (IHD) risk;

(2) alternatively other obese people may have higher intakes of nutrients with protective qualities such as polyunsaturated fatty acids of the $n-3$ series which by their effects on platelet function reduce thrombosis (Leaf \& Weber, 1988).

The second unknown factor concerns physical activity. Improvement in metabolic variables associated with obesity, (blood pressure levels, blood glucose, insulin, cholesterol and triacylglycerol levels) resulting from physical training has been observed in obese men and women (Krotkiewski \& Bjorntorp, 1986; Després et al. 1988). This questions how the fit obese person compares with the unfit obese person in terms of health.

Therefore, it is apparent that obesity is a heterogeneous disorder and that not all obese people are at the same risk of ill health. It is increasingly likely that these risk levels are not randomly determined but that a subgroup of obese persons particularly vulnerable to disease exists. In most prospective studies, due to inadequate control of the confounding factors outlined previously, this 'at risk' obese subgroup remains concealed as an indiscriminate part of the whole overweight group. Recently published, however, is a study which does allow clear identification of the vulnerable obese group and, thereby, facilitates comparison of the health risks this group experienced with those of other obese subjects. This comprises a prospective study of obesity and coronary heart disease in 115886 women who were followed up for 8 years (Manson et al. 1990). Controlling for age, cigarette smoking, menopausal status and hormone-replacement therapy, and using $\mathrm{BMI}<21$ as a reference category, the relative risk of coronary heart disease was found to be over four times greater in the most overweight women (BMI >29), whereas in the moderately overweight women $(\mathrm{BMI}>24<29)$ this was less than double. When the potent cardiovascular disease risk factors hypertension, diabetes and hyperlipidaemia were controlled for, however, the relative risk of coronary heart disease in the most overweight women $(\mathrm{BMI}>29)$ was reduced to less than double. More important was the effect of such an adjustment on the moderately overweight women (BMI $>24<29$ ) whose relative risk of coronary heart disease was reduced to that of women within the normal weight range. This finding questions the appropriateness of treating moderately overweight subjects according to weight-for-height tables when they may not be at increased risk of ill health. 


\section{INDICES OF OBESITY}

With increasing evidence that obesity is a heterogeneous disorder, there are now several obesity indices to choose from. Furthermore, different rankings of subjects may result depending on which index is used (Sjöstrom, 1986). This is discussed. Although obesity may be a condition of excess body fat, few definitions are based on measuring or estimating the fat content of the body. This is a consequence of the complexity and impracticality of the majority of existing methods of body fat estimations; one exception being the skinfold measurement method of body fat estimation. The skinfold-thickness method has, however, been criticized because it is quite prone to inter-observer error (Ruiz et al. 1971). There are ethnic differences in the distribution of subcutaneous fat (Jones et al. 1976); it is impossible to obtain skinfold measurements on very obese subjects and, until now, the relationship of percentage body fat (as measured by skinfold-thickness technique) has not been shown to have a better correlation with mortality than other more widely used obesity indices, e.g. BMI. To obtain such evidence it will be necessary to study large population samples for a long time (Garrow, 1983).

As illustrated previously, most population studies on obesity depend on measuring height and weight where weight is corrected by reference to height. This is then used as a crude indication of the body's fat content. The BMI (weight $\left.(\mathrm{kg}) /(\text { height }(\mathrm{m}))^{2}\right)$ is the weight-for-height index that is recommended for current use (Report on Obesity, 1983; National Institute of Health, 1985). It is a simple index which correlates well to other weight-height indices used (Society of Actuaries, 1959). The main advantage of BMI is that it allows for comparison of populations.

In the light of new findings in the criteria considered important for weight-height indices the uncritical use of BMI needs to be evaluated.

An index which makes all short (or tall) people appear obese is obviously not useful, which explains why many investigators believe that a basic requirement of any weight-height index is that it should have the least possible dependency on height (Florey, 1970; Keys et al. 1972; Stavig et al. 1984).

The BMI has been shown to have a low correlation with height for most adult populations (Keys et al. 1972; Garrow, 1983). Recently, however, research in Sweden suggests that the crucial question is not whether the obesity index itself is zero-correlated with height, but rather if the predictions based on the index are unbiased by height (Sjöstrom, 1986). These Swedish investigations, in finding that adipose tissue is not generally zero-correlated to height, propose two new weight-height indices:

$$
\begin{aligned}
& \text { Women: ATI }(\mathrm{kg})=1.05 \text { weight }(\mathrm{kg}) /(\text { height }(\mathrm{m}))^{0.64}-23.4, \\
& \text { BFI }(\mathrm{kg})=1.08 \text { weight }(\mathrm{kg}) /(\text { height }(\mathrm{m}))^{0.82}-28 \cdot 1, \\
& \text { Men: } \quad \text { ATI }(\mathrm{kg})=0.75 \text { weight }(\mathrm{kg}) /(\text { height }(\mathrm{m}))^{0.35}-21.4, \\
& \text { BFI }(\mathrm{kg})=1.08 \text { weight }(\mathrm{kg}) /(\text { height }(\mathrm{m}))^{0.4}-23.5,
\end{aligned}
$$

where ATI is the adipose tissue index and BFI is the body fat index.

Apparently the correlation of both these indices with height is similar to the correlation of adipose tissue with height; therefore, it is argued that ATI and BFI give predictions of adipose tissue and body fat which are unbiased by height unlike BMI (Sjöstrom, 1986). The disease prediction power of these indices have yet to be tested in prospective fashion. 
The assumption that underlies most of the work on obesity and its effects on health, is that excess adiposity is the risk factor. Using weight-for-height tables, weight becomes a surrogate for fatness. Although BMI has been shown in men to be the most closely correlated index to the skinfolds, it was shown that it could account for only a little over half the variance in adiposity (Stavig et al. 1984). This indicates that this index can best be described as a crude measure of obesity, relative body mass being a composite of fat, bone structure, muscularity etc., relative to height (Stavig et al. 1984).

Other factors which further complicate the use of BMI are discrepancies arising from the relationship between BMI and fatness which is not the same in men as in women; and which is not the same at all ages (Harrison, 1985). It has been shown that BMI $=20-25$ $\mathrm{kg} / \mathrm{m}^{2}$ closely indicates the weight-height range associated with minimum mortality (Garrow, 1983). In disease, however, the distinction between overweight and overfatness is apparent. It has been shown that overweight (BMI $>27 \cdot 8$ in men and $>27 \cdot 3$ in women), per se, may be associated with some conditions (e.g. hypertension), whereas obesity (using skinfold-thickness measurements to describe obesity) is associated with others (Van Itallie, 1985). Furthermore, Swedish investigators recently proposed an optimal risk index of body build (RIBB):

$$
\text { men: } \frac{\text { weight }(\mathrm{kg})}{(\text { height }(\mathrm{m}))^{2 \cdot 2}} ; \text { women: } \frac{\text { weight }(\mathrm{kg})}{(\text { height }(\mathrm{m}))^{4 \cdot 8}}
$$

which predicts myocardial infarction (MI). The RIBB is also based on weight-height data and is very different in men and women; and from ATI, BFI and BMI (at least for women).

Thus, it appears that several factors carrying distinct risks (adiposity, weight/mass, build) are presently described collectively as obesity, demonstrating how misleading it may be to suggest that obesity, as measured by one index only (BMI), has, or has not, an important predictive role in disease. In fact it has been reported that random misclassification, resulting from limitations of all weight indices as surrogates for body fat content, will tend to decrease the apparent magnitude of any true association between adiposity and mortality (Kleinbaum et al. 1982). Furthermore, the vulnerable subgroup of obese persons, described previously, is presently hidden away among the huge numbers of overweight individuals. Thus, the potent effects on health of this 'at risk' group, are diluted and not apparent except in large populations who are followed up for a long time. This is of particular interest to the whole question of health risks of obesity because despite these mitigating factors, obesity has been associated with increased mortality and morbidity by several studies (Simopoulos \& Van Itallie, 1984; Van Itallie, 1985; Manson et al. 1987).

\section{BODY FAT DISTRIBUTION}

The nub of obesity research and the shape of things to come involves body fat distribution. This is where the outlook for obesity has focused literally on its outline. The distribution of body fat, or adipose tissue, varies in obese and non-obese individuals. These variations are often described in terms of the easily recognized differences of fat distribution found in men and women. Both men and women have central subcutaneous and intra-abdominal fat depots; but, in addition, women have a fat depot on the upper part of the legs and in the gluteal regions. Generally, therefore, the typical obese male 
pattern of fat accumulation is the development of a powerful upper body with prominent abdomen, whereas the typical obese female pattern is relatively lean upper body with an impressive accumulation of fat in the buttocks and thighs. Although this is not an absolute sex difference (some men having some fat on their legs and some women having most of their adipose tissue in the abdominal region), it does explain why terms such as 'android' and 'gynoid' have been used to describe the different distribution of adipose tissue.

In fact 'android' and 'gynoid' were the nomenclature used by Vague (1956) when he reported how the former, though not the latter, was associated with the development of atherosclerosis, type II diabetes mellitus and gout. Since then several workers have extended Vague's (1956) original findings, although different nomenclatures and methods for assessing body fat distribution have been used. Although Vague (1956) emphasized the upper-lower body-fat dichotomy, several subsequent workers (Albrink \& Wister-Meigs, 1964; Blair et al. 1984; Ducimetière et al. 1986; Haffner et al. 1986a,b) chose to focus on the dichotomy between central (or truncal) and peripheral (or extremity) adiposity. With the advent of a relatively simple index, the waist:hip circumference ratio (WHR), the pendulum swung back again to the upper-lower dichotomy. Subsequently, it is now suggested that upper fat pattern may be distinct from a central fat pattern (Weinser et al. 1985). In fact when the morphological and metabolic diversity of various body fat depots are considered, it seems likely that more than one index will be necessary to capture the full impact of body fat pattern on metabolism.

Since 1983, the whole area of research has been blazingly active and has produced a full range of new terminology to add to Vague's 'android or gynoid' (Vague, 1956), e.g. 'apples or pears' (Ashwell et al. 1985) 'truncal or peripheral' (Blair et al. 1984; Ducimetière et al. 1986; Haffner et al. 1986a,b) 'upper or lower' (Krotkiewski et al. 1983a; Lapidus et al. 1984; Larsson et al. 1984).

It is abdominal obesity which is linked with increased disease risk and it is postulated that the 'at risk' obese persons may be this shape. However, with the different indices of abdominal obesity varying considerably in their ability to indicate disease risk, at this point in time there is no clear evidence of a single index emerging as being important. This is illustrated in the following sections.

\section{THE RISK OF BODY FAT DISTRIBUTION}

Longitudinal studies. The findings of various body-fat-distribution indices as independent risk factors for cardiovascular disease, NIDDM and perhaps female carcinomas, was a major break-through in the field, particularly after it became apparent that BMI played a different role here.

Cardiovascular disease and premature death. The Swedish Gothenburg Population Study reported in 1984 of its finding that WHR was independently predictive of MI in women (Lapidus et al. 1984). In men, this index was predictive of IHD, premature death and stroke with the interesting finding that the highest risk of IHD and death occurred in men with a low BMI but high WHR, i.e. the leanest men who had an abdominal body fat distribution (Larsson et al. 1984). In this study of men, however, the WHR was not predictive of any of the end points independently of smoking, blood pressure and serum cholesterol level. Furthermore, it was recently reported that when the length of follow-up in men was extended to 18 years the WHR was no longer predictive, even in a 
univariate way, of IHD or premature death (Larsson, 1988). Using indices other than the WHR, other prospective studies of men have found body fat distribution to be independently associated with CHD (Stokes et al. 1986; Ducimetière et al. 1986; Donahue et al. 1987). Indices used include truncal skinfold-thickness measurements (Ducimetière et al. 1986) and subscapular skinfold-thickness measurements (Stokes et al. 1985; Donahue et al. 1987). None of these studies, however, found an inverse relationship of BMI with body-fat-distribution index used.

Diabetes mellitus. The WHR has been prospectively associated with NIDDM in men and women (Ohlson et al. 1985; Lundgren et al. 1989). From these studies it seems that obesity (BMI) and body fat distribution (WHR) may act synergistically to increase risk of development of NIDDM (Bjorntorp, 1988).

Female carcinomas. Results of recent Swedish investigations suggest that body fat distribution (described by WHR or other measures of centrally located body fat) might be a stronger predictor for endometrial and ovarian carcinomas, than the BMI (Lapidus et al. 1988). This finding, however, needs confirmation by a larger study (Bjorntorp, 1988).

Cross-sectional studies. Several cross-sectional studies provide evidence of the disease association of abdominal obesity as depicted in Tables 2 and 3. From these findings several aspects of body fat distribution are apparent:

(a) the number of different indices of abdominal obesity that have been shown to have a disease association is prolific, with only a few having been examined prospectively;

(b) in several studies (see Tables 2 and 3 ) the body-fat-distribution index is more strongly associated with disease than BMI. This is not true of all studies which include overall obesity indices, e.g. percentage body fat has stronger association with hyperinsulinaemia than WHR (Folsom et al. 1989);

(c) although it appears that the disease association exists across age, sex and race, there is strong evidence that body fat distribution is influenced by these factors. Direct assessment of abdominal obesity, using computed tomography has shown increasing abdominal obesity with advancing age (Fujioka et al. 1987). In simple terms this age association with body fat distribution could be described as the inevitable 'spare tyre' development of middle age.

Similarly, computed tomography studies have shown that there is an inherent difference in abdominal fat distribution between males and females and that this is unrelated to weight (Graucer et al. 1984). Other studies found that the larger depot of abdominal fat in men is mainly due to the higher number of fat cells in that region (Krotkiewski et al. 1983a) and increased androgenic-oestrogenic activity has been observed in women with abdominal obesity (Evans et al. 1983).

Recently it has been reported from the European Fat Distribution Study that the importance of the various indices of abdominal obesity does vary according to race (Seidell et al. 1989).

The association of body fat distribution and cigarette smoking habit is of interest because it highlights how complex body fat distribution is. Cigarette smoking habit is negatively associated with BMI (Garrison et al. 1983; Manson et al. 1987) and the abdominal obesity index subscapular skinfold thickness (Donahue et al. 1987), but it is positively associated with another abdominal obesity index, the WHR (Barrett-Connor \& Khaw, 1989; Shimokata et al. 1989). Therefore, research to date leaves many unanswered questions about the true role of body fat distribution in disease. Future 


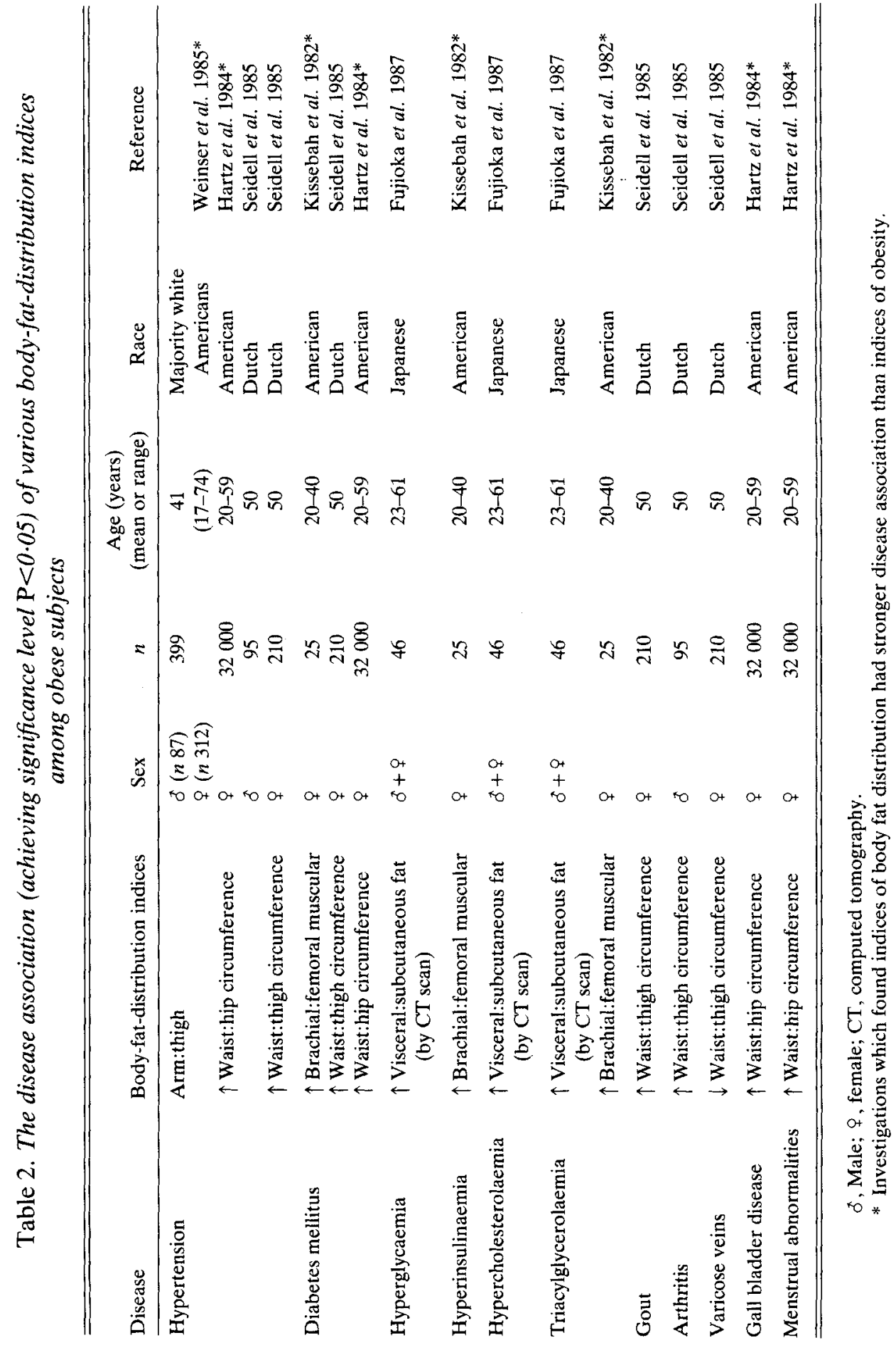




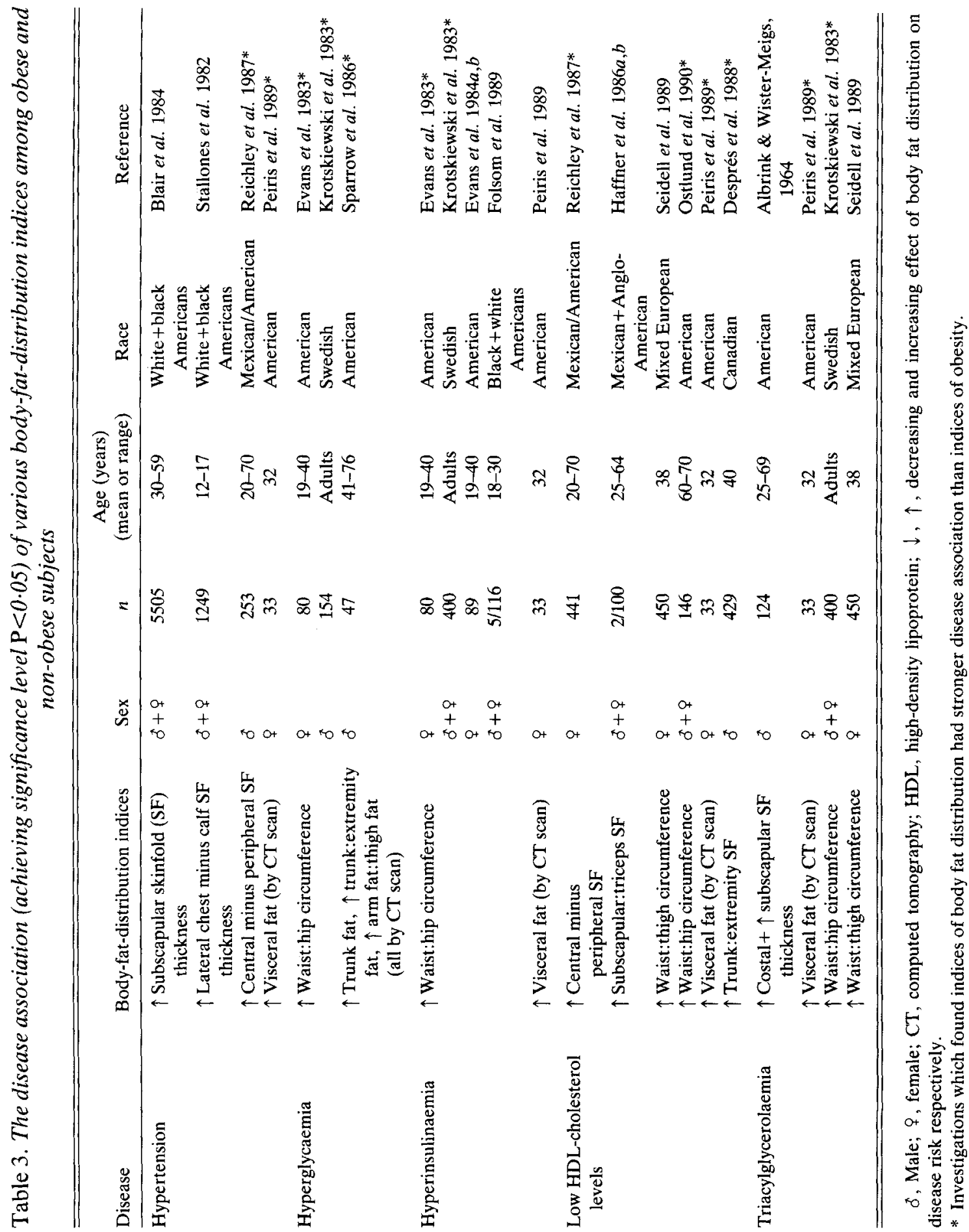


investigations must address questions such as the indices which are important and for which race, sex and age-group; and the standardization of various measurements, e.g. at what exact anatomical location should waist girth be measured? Thus, while all these developments may be very exciting in terms of characterizing the 'at risk' obese individuals, much work is needed before these indices become feasible for use in the same way as BMI.

The advent of indices of body fat distribution has resulted in rapid developments in the identification of the 'at risk' obese individuals. However, the 'pinning down' of a heterogeneous disorder such as obesity is becoming increasingly complicated. Up to recently researchers of multi-factorial diseases such as coronary heart disease, had a simple task when it came to assessing obesity risk; all it required was the inclusion of a few simple anthropometric measurements such as weight and height. Now times are rapidly changing and future students of obesity may well envy their predecessors who could tackle obesity with a few simple indices.

\section{SOCIAL AND PSYCHOLOGICAL ASPECTS OF OBESITY}

The effects of obesity on psychological and social health. Assessment of the health risks of obesity should include assessment of the psychological and social aspects of the disorder. Having described the physical consequences of being obese, the effects on psychological and social health are now examined. There is accumulating evidence of strong prejudice against obese persons (Wadden \& Stunkard, 1985; Wooley, 1987). The enormity of what this means for obese persons and the extent of contempt, they are subjected to, is seldom realized. That fatness is perceived as a mark of personal inferiority is evident from discrimination against obese persons in both academic and work settings: lower acceptance rates into high-ranking colleges have been found for obese high-school students than for normal-weight students even though the two groups did not differ in high-school performance, academic qualifications or application rates to colleges (Canning \& Meyer, 1966). A survey of employers found $16 \%$ said they would not hire obese women under any circumstances, and an additional $44 \%$ would not hire them under certain circumstances (Wadden \& Stunkard, 1985). Within the work-force it has also been shown that 'fat executives get slimmer paychecks': only $9 \%$ of those earning $\$ 25000-\$ 50000$ were more than $10 \mathrm{lb}$ overweight, compared with $39 \%$ of those earning $\$ 10000-\$ 20000$. Outside the work-place, discrimination constantly confronts the obese: even children demonstrate prejudice against obesity and regard fatness as being the fat person's own fault (Harris \& Smith, 1982). A recent study highlights how obese subjects have to live with a social handicap that is independent of parental social class, intelligence and education. This study found obese young men attain a lower social class than comparable young men from the same population (Sonn-Holm \& Sørenson, 1986). Important social interactions such as entry into marriage may be more difficult for obese persons; with one study showing that only $12 \%$ of women who moved into a higher socio-economic class were obese, while $22 \%$ moving into a lower socio-economic class were overweight (Goldblatt et al. 1965).

When obese persons seek help they often find further prejudice from the health professionals they turn to; it was found among a group of health-care professionals $(86 \%$ of whom treated obesity) that $87 \%$ thought the obese were self indulgent, $70 \%$ assumed 
they had emotional problems, $88 \%$ assumed they ate to compensate for other problems and $74 \%$ assumed they had family problems (Maiman et al. 1979).

Normal-weight persons, including health professionals, are unlikely to realize the true extent of the prejudice against obese people. This is because obese people subscribe to the majority view, i.e. regarding themselves as the cause of their own problems, thereby deserving of little sympathy (Wooley, 1987). It has been suggested that obese people appear better accepted than they really are simply because they do not challenge the social conventions that discriminate against them (Wooley, 1987). It is a chilling thought that health professionals may be among those who communicate to the obese the predominant social attitude of disapproval but are likely to be unaware of the hurtful impact of their intervention.

\section{THE CONSEQUENCES OF 'OBESITY-PHOBIA'}

A simple health message (in this case 'fat is bad') when taken too seriously brings other health problems. Weight obsession and 'obesity-phobia' are understandable when the social consequences are considered. Women are particularly vulnerable to weightobsession probably because they are subjected to more social pressures on appearance, than men (Wooley, 1987). The most serious consequences of 'obesity-phobia' are the spiralling prevalences of eating disorders such as anorexia nervosa and bulimia nervosa (Russell, 1987). Women normally have more borderline intakes of micronutrients due to their lower energy requirements and associated lower energy intakes (Lee \& Cunningham, 1990). This leaves women with less margin for dietary error. Yet women are more likely than any other group to repeatedly use 'fad' diets. The influence of medicine seems to have been lost. Countless dieters, many of whom are not overweight, are self selected and define for themselves an appropriate weight and choose, without advice, the means to achieve it. Prevalence of overweight among women has been shown to be strongly associated with low socio-economic status (Wooley, 1987). Obesity, thereby, further inflates the inequalities of life that burden the poor, with lower rates of employment (Wadden \& Stunkard, 1985) and admission to high-ranking colleges of obese women (Canning \& Meyer, 1966). Within Western populations large groups of vulnerable obese people exist at the mercy of countless profit-oriented groups offering various techniques to combat obesity. The safety of some of these techniques is questionable, particularly when used by normal-weight individuals. Our task as health professionals involved in treatment of obesity must include treatment of the aversion to obesity that far outweighs its health risks. It would appear that in this regard, we need to treat not only our patients but also ourselves and society at large.

\section{WHY SLIM?}

There is a high incidence of overweight and obesity in the developed world and, because of the health risks described, obese people need to make serious efforts to reduce their weight. This section examines the advantages and disadvantages of slimming.

The advantages. Only very limited information is available on the effects of weight reduction on mortality and this is confined to life insurance data. In these studies, people who lost weight, and thereby became eligible for standard insurance, experienced a decline in mortality ratios to levels comparable with persons of average weight. Mortality 
declined from 128 to $109 \%$ for those initially $25 \%$ overweight, and from 151 to $96 \%$ for those initially 35 to $40 \%$ overweight (Society of Actuaries, 1959; Manson et al. 1987).

Improvements in coronary heart disease risk factors (hypertension, diabetes and hyperlipidaemia) are associated with weight loss in most slimmers, e.g. even small decreases in body-weight can lower blood pressure levels in obese hypertensives (Reisin et al. 1978); conventional teaching emphasizes diet therapy and weight loss for obese patients with diabetes (National Institute of Health, 1987) and hyperlipidaemia (The Expert Panel, 1988).

As described previously, weight reduction in morbid obesity can cause complete regression of threshold conditions of severe obesity, e.g. pulmonary and renal dysfunction and infertility. The improvement in mobility gained by obese persons with arthritis or respiratory disease on weight loss, is a well recognized benefit of slimming (Report on Obesity, 1983).

Although information is limited at present, it would appear that body fat distribution can be altered by weight reduction. Small studies on women have shown that WHR is more resistant to change, on weight reduction, than waist:thigh ratio (Ashwell et al. 1986). Other work suggests that smaller losses of weight achieve alteration of WHR when dieting is combined with exercise (Krotkiewski, 1988). These alterations in body fat distribution coincide with improvements in metabolic variables.

The disadvantages. There appears to be considerable individual variation in health improvements gained on weight loss, and not all slimmers show improvement in coronary-heart-disease risk-factor profile on weight reduction, e.g. although diet therapy is considered the cornerstone of therapy for obese patients with NIDDM, plasma glucose levels do not always improve after weight loss (Watts et al. 1990). Similarly, men seem to show an increase in high-density-lipoprotein-cholesterol concentrations on slimming, whereas women often do not (Brownell \& Stunkard, 1981). It may transpire that individuals whose health improves on slimming will be identified according to their body fat distribution. It has been reported that not only do obese women with greater abdominal obesity achieve greater reductions in WHR on similar weight loss, but that this coincides with greater improvements in metabolic variables (blood glucose and serum lipids levels) than those with gluteal-femoral obesity (Després et al. 1988). Because surgical intervention is usually warranted in the treatment of morbid obesity, the benefits of weight loss to these patients has to be balanced against the short- and long-term risks of such surgery (Kral, 1985). The poor success rates of slimming have to be considered. If a 'cure' for obesity is defined as reduction to desired weight for 5 years, it is more likely that a person will be cured of most forms of cancer than of obesity (Brownell, 1982). If this was considered seriously by obese 'would-be slimmers' it is almost certain that most would question 'why slim?'. Adverse psychological effects such as depression and pre-occupation with food have been documented in patients on weight-reduction diets (Stunkard, 1957). However, behaviour modification used in conjunction with diet therapy seems to reduce this (Wing et al. 1984). Therefore, to answer the 'why slim?' question, the advantages must be balanced against the disadvantages for each case. This necessitates individual assessment of all overweight-obese people.

The epidemiology of overweight/obesity. Information on how many adults, in Ireland (Southern Ireland only) and the UK, currently in need of such an assessment to weigh up the gains and losses of slimming, is given in Figs 2 and 3. These graphs depict the 


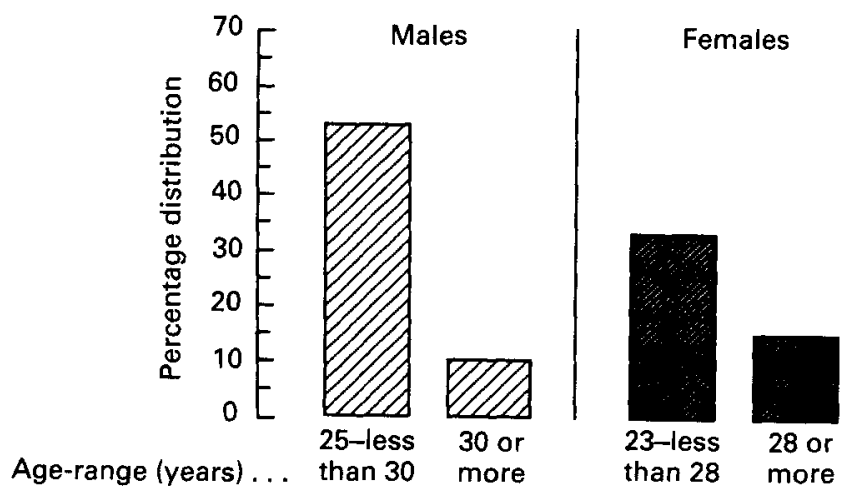

Fig. 2. The prevalence of overweight and obesity in Ireland, 1990: percentage distribution of overweight by sex (18-60 years). From Lee \& Cunningham (1990).

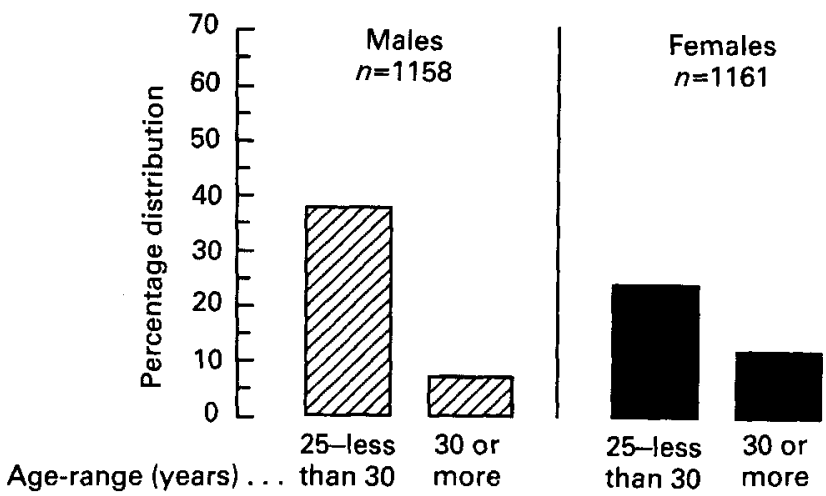

Fig. 3. The prevalence of overweight and obesity in the UK: percentage distribution of body mass index (weight/height ${ }^{2}$ ) by sex. From Gregory et al. (1990).

current percentages of overweight and obese men and women in both countries. These percentages result from the blanket application of the numbers found in the weight-forheight tables in representative samples of adults (Gregory et al. 1990; Lee \& Cunningham, 1990).

In Ireland $63 \%$ of all males and $48 \%$ of all females are overweight and in the UK $45 \%$ of all males and $36 \%$ of all females (using higher cut-off points for diagnosis of overweight) are overweight. Resources obviously cannot cover assessment of all these adults.

\section{WHO SHOULD SLIM?}

An overall 'Fat is Bad' message to those relatively overweight populations, is not a good public health strategy. First, all obese people are not at high risk and, second, such messages fuel weight obsession. What is needed is the identification of the 'at risk' obese people so that those truly at increased risk of ill health can be targeted for treatment. Besides ensuring better care for those most in need, such a strategy could be expected to 
Table 4. Who should slim? obesity risk assessment profile

BMI $\geqslant 30$
or
BMI $>25+$ Age <40 years
or + Hypertension
or + Diabetes
or + Hyperlipidaemia
or + Cigarette smoking habit
or + Central distribution of body fat

BMI, body mass index (weight/height ${ }^{2}$ ).

cause some diminution in the epidemic of weight obsession. It is likely that once the public become aware that not all obese people are at the same level of risk, the problem of weight obsession may recede, e.g. women, who are the most weight-obsessive group, may even begin to regard fat accumulation on the thighs with pleasure, as the health benefits of gynoid-shape become more apparent.

In order to start using what is known about the identification of 'at risk' obese persons, the use of a simple risk-factor profile (similar to that used in the assessment of hyperlipidaemia (The Expert Panel, 1988)), should be promoted. An outline of such an obesity risk assessment profile is presented in Table 4. Overweight persons being positive for any of these factors could be described as 'at risk'. Degree of risk could be determined from the severity of the factor or the number of adverse factors positive.

In conclusion, it is by the identification of the 'at risk' obese group that a major step in tackling the health aspects of 'why slim?' can be taken. There is a need for health professionals in the field to start using what is known about the characteristics of vulnerable obese persons so that they can be targeted for better care. In order to facilitate this a tool for obesity risk assessment is needed. This must be feasible for clinical use if it is to become a simple adjunctive to the easy-to-use weight-for-height tables. The tool proposed in the present article is the obesity risk assessment profile.

\section{REFERENCES}

Albrink, M. \& Wister-Meigs, J. (1964). Inter-relationship between skinfold thickness, serum lipids and blood sugar in normal men. American Journal of Clinical Nutrition 15, 255-261.

Andres, R. (1980). Effect of obesity on total mortality. International Journal of Obesity 4, 381-386.

Andres, R., Elahi, D., Tobin, J. D., Muller, D. C. \& Brant, L. (1985). Impact of age on weight goals. Annals of Internal Medicine 103, 1030-1033.

Ashwell, M. A., Cole, T. J. \& Dixon, A. K. (1985). Obesity: new insight into the anthropometric classification of fat distribution shown by computed tomography. British Medical Journal 290, 1692-1694.

Ashwell, M. A., McCall, S. A., Cole, T. J. \& Dixon, A. K. (1986). Fat distribution and its metabolic complications: interpretations. In Human Body Composition and Fat Distribution. EURONUT Report no. 8, pp. 227-242 [N. G. Norgen, editor]. Wageningen: EURONUT.

Barrett-Connor, E. L. \& Khaw, K. T. (1989). Cigarette smoking and increased central adiposity. Annals of Internal Medicine 111, 783-787.

Bjorntorp, P. (1988). The association between obesity, adipose tissue distribution and disease. Acta Medica Scandinavica 723, 121-134.

Blair, D., Haluche, J. P., Simo, C. A. H., Sylvester. D. \& Abraham, S. (1984). Evidence for an increased risk for hypertension with centrally located body fat and the effects of race and sex on this risk. American Journal of Epidemiology 119, 526-540. 
Bray, G. A. (1985). Complications of obesity, Annals of Internal Medicine 103, 1052-1062.

Brownell, K. D. (1982). Obesity: understanding and treating a serious, prevalent and refractory disorder. Journal of Consultant Clinical Psychology 50, 820-840.

Brownell, K. D. \& Stunkard, A. J. (1981). Differential changes in plasma high-density lipoprotein cholesterol levels in obese men and women during weight-reduction. Archives of Internal Medicine 141, 1142-1146.

Buchwald, H., Lober, P. H. \& Varco, R. L. (1974). Liver biopsy findings in seventy-seven consecutive patients undergoing jejuno-ileal bypass for morbid obesity. American Journal of Surgery 127, 48-52.

Burnwell, C. S., Robin, E. D., Whaley, R. D. \& Bickelman, A. G. (1956). Extreme obesity associated with alveolar hypoventilation: A Pickwickian Syndrome. American Journal of Medicine 21, 811-818.

Canning, H. \& Meyer, J. (1966). Obesity - its possible effects on college acceptance. New England Journal of Medicine 275, 1171-1174.

Després, J. P., Tremblay, A., Nadeau, A. \& Bouchard, C. (1988). Physical training and changes in regional adipose tissue distribution. Acta Medica Scandinavica 723, Suppl., 205-212.

Donahue, R. P., Bloom, E., Yano, K., Abbott, E. D. \& Reed, D. M. (1987). Central obesity and coronary heart disease in men. Lancet $\mathrm{i}, 821-824$.

Ducimetière, P., Richard, J. \& Cambien, F. (1986). The pattern of subcutaneous fat distribution in middle aged men and the risk of coronary heart disease. The Paris Prospective Study. International Journal of Obesity 10, 229-240.

Evans, D. J., Hoffman, R. G., Kalkhoff, R. K. \& Kissebah, A. H. (1983). Relationship of androgenic activity to body fat topography, fat cell morphology and metabolic aberrations in premenopausal women. Journal of Clinical Endocrinology and Metabolism 57, 304-310.

Evans, D. J., Hoffman, R. G., Kalkhoff, R. K. \& Kissebah, A. H. (1984a). Relationship of body fat topography to insulin sensitivity and metabolic profiles in premenopausal women. Metabolism 33, 68-75.

Evans, D. J., Murray, R. \& Kissebah, A. H. (1984b). Relationship between skeletal muscle insulin resistance, insulin mediated glucose disposal and insulin binding. Journal of Clinical Investigation 74, 1515-1525.

Florey, C. V. (1970). The use and interpretation of pondermal index and other weight-height ratios in epidemiological studies. Journal of Chronic Disease 23, 93-103.

Folsom, A. R., Barke, G. L., Ballew, C., Jacob, D. R., Haskell, W. L., Donahue, R. P., Liu, K. \& Hilner, J. E. (1989). Relation of body fatness and its distribution to cardiovascular risk factors in young blacks and whites. The role in insulin. American Journal of Epidemiology 130, 911-924.

Friedman, G. D., Kannel, W. B. \& Dawber, J. R. (1966). The epidemiology of gallbladder disease: observations in the Framingham Study. Journal of Chronic Disease 19, 273-292.

Fujioka, S., Matsuzawa, Y., Tokunage, K. \& Tarin, S. (1987). Contribution of intra-abdominal fat accumulation to the impairment of glucose and lipid metabolism in human obesity. Metabolism 36, 54-59.

Garrison, R. J., Feinleib, M., Castelli, W. P. \& McNamara, P. M. (1983). Cigarette smoking as a confunder of the relationship between relative weight and long term mortality: the Framingham Study. Journal of the American Medical Association 249, 2199-2203.

Garrow, J. G. (1983). Indices of adiposity. Nutrition Abstracts and Reviews 53, 697-708.

Glass, A. R., Dahma, W. T., Abraham, G., Atkinson, R. L., Bray, G. A. \& Swerdloff, R. S. (1978). Secondary amenorrhoea in obesity: etiologic role of weight related androgen excess. Fertility and Sterility 30, 243-244.

Goldblatt, P. B., Moore, M. E. \& Stunkard, A. J. (1965). Social factors in obesity. Journal of the American Medical Association 192, 1039-1044.

Graucer, W. A., Mois, A. A., Cann, C. E. \& Goldberg, M. I. (1984). Quantification of body fat distribution in the abdomen using computed tomography. American Journal of Clinical Nutrition 39, 631-637.

Gregory, J., Foster, K., Tyler, H. \& Wiseman, M. (1990). The Dietary and Nutritional Survey of British Adults. Office of Population Censuses and Surveys. London: H.M. Stationery Office.

Haffner, S. M., Stern, M. P. \& Hazuda, H. P. (1986a). Upper body and centralized adiposity in Mexican Americans and non-hispanic whites: relationship to body mass index and other behavioural and demographic variables. International Journal of Obesity 10, 493-502.

Haffner, S. M., Stern, M. P., Hazuda, H. P., Rosenthal, M. \& Knapp, A. (1986b). The role of behaviour variables and fat patterning in explaining ethnic differences in serum lipids and lipoproteins. American Journal of Epidemiology 123, 830-839.

Harris, M. B. \& Smith, S. D. (1982). Beliefs about obesity: effects of age, ethnicity, sex and weight. Psychological Reports 51, 1048-1055.

Harrison, G. G. (1985). Definition of obesity. Height-weight tables. Annals of Internal Medicine 103, 989-994. 
Hartz, A. J., Barboriak, P. N., Wong, A., Katayama, K. P. \& Rimm, A. A. (1979). The association of obesity with infertility and related menstrual abnormalities in women. International Journal of Obesity 3, 57-73.

Hartz, A. J., Rupley, D. C. \& Rimm, A. A. (1984). The association of girth measurements with disease in 32,856 women. American Journal of Epidemiology 119, 71-80.

Hubert, M. B., Feinleib, M., McNamara, P. M. \& Castelli, N. P. (1983). Obesity as an independent risk factor for cardiovascular disease: a 26 year follow-up of participants on the Framingham Heart Study. Circulation 67, 968-977.

Jones, P. R. M., Bharadwaj, H., Bhatia, M. R. \& Malhotra, M. S. (1976). Differences between ethnic groups in relationship of skinfold thickness to body density. In Selected Topics in Environmental Biology, pp. 373-376 [B. Bhatin, G. S. Chhinna and B. Singh, editors]. New Delhi: Interprint Publications.

Kannel, W. B. \& Gordon, T. (1979). Physiological and medical concomitants of obesity: The Framingham Study. In Obesity in America. DHEW Publication no. (NIH) 79-359, [G. A. Bray, editor]. Bethesda, Maryland: National Institute of Health.

Keys, A. (1980). Seven countries: A Multivariate Analysis of Diet and Coronary Heart Disease. Cambridge, Massachusetts: Harvard University Hospital Press.

Keys, A., Fidanza, F., Katwonen, M. J., Kimera, N. \& Taylor, M. L. (1972). Indices of relative weight and obesity. Journal of Chronic Disease 25, 329-343.

Kissebah, A., Vydelingum, N., Murray, R., Evans, D. J., Martz, A. J., Kalkhoff, R. K. \& Adams, P. W. (1982). Relation of body fat distribution to metabolic complications of obesity. Journal of Clinical Endocrinology and Metabolism 54, 254-260.

Kleinbaum, D. G., Kupper, L. L. \& Morganstern, H. (1982). Epidemiological Research: Principles and Quantitative Methods, pp. 223-224. Belmont, California: Lifetime Learning Publications.

Kopelman, P. G., White, N., Pilkington, T. R. E. \& Jeffcoate, S. L. (1981). The effect of weight loss on sex steroid excretion and binding in massively obese women. Clinical Endocrinology 15, 113-116.

Kral, J. G. (1985). Morbid obesity and related health risks. Annals of Internal Medicine 103, 1043-1047.

Krotkiewski, M. (1988). Can body-fat patterning be changed. Acta Medica Scandinavica 123, Suppl., $213-223$.

Krotkiewski, M. \& Bjorntorp, P. (1986). Muscle tissue in obesity with different distributions of adipose tissue. Effects of physical training. International Journal of Obesity 10, 331-341.

Krotkiewski, M., Bjorntorp, P., Sjostrom, L. \& Smith, U. (1983a). Impact of obesity on metabolism of men and women. Journal of Clinical Investigation 72, 1150-1162

Krotkiewski, M., Bybund-Fallenuis, A. C., Holm, J., Bjorntorp, P., Grimby, G. \& Mandeoukas, K. (1983b). Relationship between muscle morphorism and metabolism in obese women: the effects of long-term physical training. European Journal of Clinical Investigation 13, 5-12.

Lapidus, L., Bingtsson, L., Larrson, B., Pennart, K., Rybo, E. \& Sjostrom, L. (1984). Distribution of adipose tissue and risk of cardiovascular disease and death: a 12 year follow up of participants in the population study of women in Gothenburg, Sweden. British Medical Journal 289, 1257-1261.

Lapidus, L., Helgesson, O., Merck, C. \& Björntorp, P. (1988). Adipose tissue distribution and female carcinomas. A 12 year follow up of participants in the population study of women in Gothenburg, Sweden. International Journal of Obesity 12, 361-368.

Larsson, B. (1988). Regional obesity as a health hazard in men-prospective studies. Acta Medica Scandinavica 723, Suppl., 45-51.

Larsson, B., Suardsudd, K., Welin, L., Wilhelnmsen, L., Bjorntorp, P. \& Tibblin, G. (1984). Abdominal adipose tissue distribution, obesity and risk of cardiovascular disease and death: a 13 year follow up of participants in the study of men born in 1913. British Medical Journal 288, 1401-1404.

Leaf, A. \& Weber, P. C. (1988). Cardiovascular effects of N-3 fatty acids. New England Journal of Medicine 318, 549-557.

Lee, P. \& Cunningham, K. (1990). Irish National Nutrition Survey. Dublin: INDI.

Lew, E. A. (1985). Mortality and weight: Insured lives and the American Cancer Society Studies. Annals of Internal Medicine 103, 1024-1029.

Lew, E. A. \& Garfinkel, L. (1979). Variations in mortality by weight among 750,000 men and women. Journal of Chronic Disease 32, 563-576.

Lundgren, H., Bengtsson, C., Blohme, G., Lapidus, L. \& Sjöstrom, L. (1989). Adiposity and adipose tissue distribution in relation to incidence of diabetes in women. Results from a prospective population study in Gothenburg, Sweden. International Journal of Obesity 13, 413-423.

Maiman, L. A., Wang, V. L., Becker, M. H., Finlay, J. \& Simonson, M. (1979). Attitudes towards obesity and the obese among professionals. Journal of the American Dietetic Association 74, 331-336. 
Manson, J. E., Coldirz, G. A., Stampfer, M. J., Willett, W. G., Rosner, B., Manson, R. R., Speizer, F. E. \& Hennekens, C. H. (1990). A prospective study of obesity and risk of coronary heart disease. New England Journal of Medicine 322, 882-889.

Manson, J. E., Stampfer, M. J., Hennekens, C. H. \& Willett, W. C. (1987). Body weight and longevity - a reassessment. Journal of the American Medical Association 257, 353-358.

Meyskens, F. L. (1990). Coming of age - the chemoprevention of cancer. New England Journal of Medicine 323, 825-827.

National Institute of Health (1985). Consensus development conference statement. Annals of International Medicine 103, 1073-1077.

National Institute of Health (1987). Consensus development conference statement on diet and exercise in non-insulin-dependent diabetes mellitus. Diabetes Care 10, 639-644.

Ohlson, L. O., Larsson, B., Svardsudd, K., Welin, L., Eriksson, H., Wilhelnmsen, L., Bjorntorp, P. \& Tibblin, G. (1985). The influence of body fat distribution on the incidence of diabetes mellitus 13.5 years follow-up of the participants in the study of men born in 1913. Diabetes 34, 1055-1058.

Ostlund, R. E., Staten, M., Kohrt, W. M., Schultz, J. \& Malley, M. (1990). The ratio of waist-to-hips circumference, plasma insulin level and glucose intolerance as independent predictors of the $\mathrm{HDL}_{2}$ cholesterol level in older adults. New England Journal of Medicine 322, 229-233.

Peiris, A. N., Sothmann, M. S., Hoffman, G., Hennes, M. I., Wilson, C. R., Gustalen, A. B. \& Kissebah, A. H. (1989). Adiposity, fat distribution and cardiovascular risk. Annals of International Medicine 110, 867-872.

Rabkin, S. W., Mathewson, F. A. L. \& Hsu Ping-Hiva (1977). Relation of body weight to development of ischaemic heart disease in a cohort of young North American men after a 26 year observation period. The Manitoba Study. American Journal of Cardiology 39, 452-458.

Reichley, K., Mueller, W. H., Harris, C. L., Joos, S. K., Tullach, B. R., Barton, S. \& Schull, W. J. (1987). Centralised obesity and cardiovascular disease risk in Mexican Americans. American Journal of Epidemiology 125, 373-386.

Reisin, E., Abel, R., Modan, M., Silverburg, D. S., Eliahou, H. E. \& Modan, B. (1978). Effect of weight loss without salt restriction on the reduction of blood pressure in overweight hypertensive patients. New England Journal of Medicine 298, 1-6.

Report on Obesity (1983). The metabolic consequences of overweight and obesity. Journal of the Royal College of Physicians, London 17, 6-24.

Rhoads, G. G. \& Kagan, A. (1983). The relation of coronary disease, stroke and mortality to weight in youth and middle age. Lancet i, 492-495.

Ruiz, T., Colley, J. R. T. \& Hamilton, P. J. S. (1971). Measurement of triceps skinfold thickness an investigation of sources of variation. British Journal of Preventative and Social Medicine 25, 165-167.

Russell, G. F. M. (1987). Anorexia and bulimia nervosa: penalties for fashionable slimness. In Body Weight Control - The Physiology, Clinical Treatment and Prevention of Obesity, pp. 160-169 [A. E. Bender and L. J. Brooks, editors]. Edinburgh, London, Melbourne and New York: Churchill Livingstone.

Seidell, J. C., Agolini, M., Charzewska, J., Ellsinger, B. M., Di Base, G., Björntorp, P., Hautvast, J. G. A. T., Contraldo, J., Szostak, V. \& Scuro, L. A. (1989). Indicators of fat distribution, serum lipids blood pressure in European women born in 1948 - The European Fat Distribution Study. American Journal of Epidemiology 130, 53-65.

Seidell, T. C., Bakx, J. L., Be Boer, E., Deurenberg, P. \& Hautvast, J. G. A. (1985). Fat distribution of overweight persons in relation to morbidity and subjective health. International Journal of Obesity 9 , 363-374.

Shimokata, H., Muller, D. C. \& Andres, R. (1989). Studies in the distribution of body fat. III. Effects of cigarette smoking. Journal of the American Medical Association 261, 1169-1173.

Simopoulos, A. P. \& Van Itallie, T. (1984). Body weight, health and longevity. Annals of Internal Medicine 100, 285-295.

Sjöstrom, L. (1986). New aspects of weight-for-height indices and adipose tissue distribution in relation to cardiovascular risk and total adipose tissue volume. In Recent Advances in Obesity Research. V, Proceedings of the Sth International Congress on Obesity 1986, pp. 66-76 [E. M. Berry, editor]. London, Paris: John Libbey.

Society of Actuaries (1959). New weight standards for men and women. Statistical Bulletin of $N$.Y. Metropolitan Life Insurance Co. 40, 1-4.

Society of Actuaries (1980). Build Study, 1979. Philadelphia: Recording and Statistical Corporation. 
Sonn-Holm, S. \& Sørensen, T. I. A. (1986). Prospective study of attainment of social class of severely obese subjects in relation to parental social class, intelligence and education. British Medical Journal 292, 586-589.

Sparrow, D., Borkan, G. A., Guazof, S. G., Wisnewski, C. \& Gilbert, C. K. (1986). Relationship of fat distribution to glucose tolerance. Diabetes 35, 411-415.

Stallones, L., Mueller, W. H. \& Chystenson, B. L. (1982). Blood pressure, fatness and fat patterning among USA adolescents from two ethnic groups. Hypertension 4, 483-486.

Stavig, G. R., Leonard, A. R., Igra, A. \& Felten, P. (1984). Indices of relative body weight and ideal weight charts. Journal of Chronic Disease 37, 255-262.

Stokes, J., Garrison, R. J. \& Kannel, W. B. (1986). The independent contribution of various indices of obesity to the 22 year incidence of coronary heart disease: the Framingham Heart Study. Proceedings of the International Symposium on the Metabolic Complications of Human Obesities, Marseilles, pp. 49-57. Amsterdam: Elsevier.

Stunkard, A. J. (1957). The dieting depression: untoward responses to weight reduction. American Journal of Medicine 23, 77-86.

The Expert Panel (1988). Report on the national cholesterol education program. Expert panel of detection, evaluation and treatment of high blood cholesterol in adults. Archives International Medicine 148, 36-69.

The Pooling Project Research Group (1978). Relationships of blood pressure serum cholesterol, smoking habit, relative weight and E.C.G. abnormalities to incidence of major coronary events. Final report of the Pooling Project. Journal of Chronic Disease 31, 201-306.

Vague, J. (1956). The degree of masculine differentiation of obesities; a factor determining predisposition to diabetes, atherosclerosis, gout and uric calculus disease. American Journal of Clinical Nutrition 4, 20-34.

Vandenbrouche, J. P., Mauritz, B. J., de Bruin, A., Verhessen, J. H. H., Van der Heide-Wessel, C. \& Van der Heide, R. M. (1984). Weight, smoking and mortality. Journal of the American Medical Association 252, 2859-2860.

Van Itallie, T. B. (1985). Health implications of overweight and obesity in the United States. Annals of Internal Medicine 103, 983-988.

Victor, D. W., Jr, Sarmiento, C. F., Yanta, M. \& Halverston, J. D. (1984). Obstructive sleep apnea in the morbidly obese: an indication for gastric bypass. Archives of Surgery 119, 970-972.

Wadden, T. A. \& Stunkard, A. J. (1985). Social and psychological consequences of obesity. Annals of Internal Medicine 103, 1062-1067.

Wannamethee, G. \& Shaper, A. G. (1989). Body weight and mortality in middle aged British men: impact of smoking. British Medical Journal 299, 1497-1502.

Watts, N. B., Spanheimer, R. G., Di Girolama, M., Gebhart, S. S. P., Musey, V. C., Siddig, Y. K. \& Phillips, L. S. (1990). Prediction of glucose response to weight in patients with non-insulin-dependent diabetes mellitus. Archives of Internal Medicine 150, 803-806.

Weinser, R. L., Norris, D. J, Birch, R., Bernstein, R. S., Wang, J., Guang, U., Pierson, R. U. \& Van Itallie, J. (1985). The relative correlation of body fat and fat pattern to blood pressure level. Hypertension $\mathbf{5}$, $578-585$

Weisinger, J. R., Kempson, R. L., Eldridge, F. L. \& Sivenson, R. S. (1974). The Nephrotic Syndrome: a complication of massive obesity. Annals of Internal Medicine 81, 440-447.

Wing, R. R., Epstein, L. H., Marcus, M. D. \& Kupfer, D. J. (1984). Mood changes in behavioural weight loss programmes. Journal of Psychosomatic Research 28, 189-196.

Wooley, S. C. (1987). Psychological and social aspects of obesity. In Body Weight Control - The Physiology, Clinical Treatment and Prevention of Obesity. pp. 81-89 [A. E. Bender and L. J. Brooks, editors]. Edinburgh, London, Melbourne and New York: Churchill Livingstone. 